\title{
Jacques Lecoq e a Antropologia do gesto de Marcel Jousse
}

\author{
Jacques Lecoq et L'Anthropologie du Geste de \\ Marcel Jousse
}

Ismael Scheffler

Doutor em Teatro. Professor no Departamento Acadêmico de

Design da Universidade Tecnológica Federal do Paraná ismaelcuritiba2@gmail.com ORCID: https://orcid.org/0000-0001-8827-808X

\section{RESUMO:}

Este artigo trata da pedagogia teatral do francês Jacques Lecoq e faz relação com os estudos da Antropologia do gesto, de Marcel Jousse. O estudo tem caráter histórico e conceitual. Explora como Lecoq tomou conhecimento das pesquisas de Jousse e indica influências sobre seu ensino, notadamente no que tange ao 'mimo' e no oferecimento de um vocabulário mais apropriado a sua pesquisa. São utilizadas diferentes fontes documentais, como artigos raros de periódicos, pesquisas acadêmicas, entrevistas e documentários, a maior parte em língua francesa e inéditos no Brasil. Apresenta-se aqui, Jousse, pouco conhecido no Brasil, e alguns conceitos-chave de suas pesquisas.

Palavras-chave: Jacques Lecoq. Marcel Jousse. Mimismo.

\section{RESUMÉ:}

Cet article traite de la pédagogie théâtrale du français Jacques Lecoq établissant des relations avec les études de L'Anthropologie du geste de Marcel Jousse. L'étude est à la fois historique et conceptuelle. II explore comment Lecoq a fait connaissance de la recherche de Jousse et il fait remarquer des influences sur son enseignement, notamment en ce qui concerne le mime et sur un vocabulaire plus approprié à ses recherches. Différentes sources documentaires sont utilisées, telles que de rares articles de périodiques, des recherches universitaires, des bibliographies, des interviews et des documentaires, dont la plupart n'ont pas été publiés au Brésil. Jousse, peu connu au Brésil, est présenté ainsi que quelques concepts clés de ses recherches. 
Mots clés: Jacques Lecoq. Marcel Jousse. Mimisme.

Artigo recebido em 16/01/2019

Artigo aprovado em 21/03/2019

\section{Introdução}

A pedagogia teatral de Jacques Lecoq (1921-1999) se caracteriza pela tradição oral. Ele acreditava que o verdadeiro aprendizado se dá pela vivência. As publicações atribuídas a Lecoq são, em significativa parte, decorrentes de conferências transcritas ou de entrevistas, como sua principal obra Le corps poétique (1997) [O corpo poético]. Lecoq também não se preocupava em determinar suas fontes de influência. Por vezes, mencionava referências, porém sem especificar os aspectos em que se relacionavam com sua pedagogia.

Uma das referências apontadas são as pesquisas do antropólogo francês Marcel Jousse (1886-1961). Este também publicou pouco em vida e defendia a pesquisa experimental e o ensino de relação direta. Graças a pessoas interessadas por seus estudos, publicações póstumas foram feitas, o que preservou e difundiu suas investigações.

Este artigo explora alguns aspectos da pedagogia de Lecoq em relação aos estudos de Jousse. Caracteriza-se por um estudo histórico e conceitual e procura recompor no tempo o provável ponto no qual Lecoq tomou conhecimento de Jousse e seus estudos e verificando possíveis impactos no delineamento de seu ensino.

O presente estudo está baseado em fontes documentais, utiliza artigos de periódicos, pesquisas acadêmicas, entrevistas e documentários, a maior parte em língua francesa e inéditos no Brasil - muitos são raros mesmo na França.

SCHEFFLER, Ismael. Jacques Lecoq e a antropologia do gesto de Marcel Jousse. PÓS:Revista do Programa de Pós-graduação em Artes da EBA/UFMG. v.9, n.17: mai.. 2019. Disponível em <https://eba.ufmg.br/revistapos>

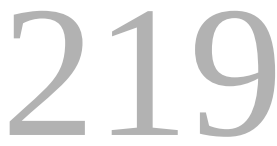


No primeiro momento, serão observadas as diferentes denominações dadas à escola de Lecoq, constatando-se haver uma dificuldade em relação ao uso do termo mimo para designar sua pesquisa e ensino.

Num segundo momento, apresenta-se uma análise de algumas das primeiras publicações de Jacques Lecoq. Os textos abrangem o período de 1967 a 1972. Essa análise visa verificar o vocabulário utilizado por Lecoq, constatando-se haver a utilização de termos mais precisos após 1969, o que é atribuído à publicação de L'Anthropologie du geste, de Marcel Jousse, nesse ano. Assim, serão reconhecidos conceitos em comum entre Lecoq e Jousse. Também serão identificados estudos nos quais Jousse foi citado como uma referência teórica para Lecoq.

O artigo ainda traz uma breve apresentação de Jousse e sua produção teórica, considerando-se o pouco conhecimento que se tem sobre suas obras no Brasil e mesmo na academia francesa. ${ }^{1}$

Por fim, serão feitas considerações sobre vinculações do teatrista com a Associação Marcel Jousse, com foco, ao menos em parte, no reconhecimento de confluências tanto de Lecoq quanto de Jousse.

O presente estudo representa um recorte de minha pesquisa de doutorado ${ }^{2}$ aqui revista para a publicação deste artigo.

\section{Sobre a dificuldade inicial do termo mimo}

Em dezembro de 1956, pouco depois de regressar da Itália, onde permaneceu por oito anos, Lecoq começou um curso que é tido como a fundação de sua própria escola de teatro. Começou modestamente, em um pequeno estúdio com apenas um aluno (VERNOIS; HERRY, 1988). Com os seus contatos, Lecoq estabeleceu um grupo e, progressivamente, sua escola ganhou corpo e fama internacional. Em 1972, alunos de mais de 50 nacionalidades já tinham passado pela escola (LECOQ, 1972) - atualmente esse número já passa de 80.

SCHEFFLER, Ismael. Jacques Lecoq e a antropologia do gesto de Marcel Jousse. PÓS:Revista do Programa de Pós-graduação em Artes da EBA/UFMG. v.9, n.17: mai. 2019. Disponível em <https://eba.ufmg.br/revistapos>

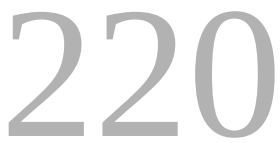


A denominação da escola mudou, já nos primeiros anos de sua existência, especialmente em decorrência das dificuldades que Jacques Lecoq enfrentava para tentar fazer entender em que consistia sua proposta de ensino:

Ela passou de "Curso de Mimo" à "Escola de Teatro"; eu, contudo, conservei a palavra mimo, que se tornara um clichê formal e esclerosado e que eu tentava ampliar para torná-lo um ponto de partida do teatro e não um fim. Fiquei tentado a chamá-la "Escola do Movimento", mas ela teria sido limitada a uma escola de ginástica, quando se tratava daquela em que "Tudo se move". As palavras me aborreciam e eu não conseguia definí-la pelo catálogo usual da arte dramática. Finalmente eu a chamei de Escola de Mimo e de Teatro. ${ }^{3}$ (LECOQ, 1976, p. 1).

O nome da escola ainda foi alterado mais vezes: “Eu a defini: 'Escola de mimo' e como subtítulo, 'Formação do ator'. Em seguida, eu lhe dei o título 'Mimo, Movimento, Teatro', por corresponder melhor a minha concepção e a minha prática pedagógica." (LECOQ, 1987a, p. 112). As denominações revelam a busca de Lecoq por uma terminologia mais clara. Assim, a mimo e teatro, adicionou, entre os dois, o vocábulo movimento, passando de École de Mime: Formation du Comédien para École Lecoq: Mime, Mouvement, Théâtre, antes de assumir a designação de escola internacional e se chamar École Internationale de Théâtre Jacques Lecoq [Escola Internacional de Teatro Jacques Lecoq] (LECOQ, 1987a), em atividade ainda hoje em Paris. $^{4}$

O termo mimo esteve presente no nome da escola por cerca de 20 anos. Isso teve grande influência sobre o trabalho de Lecoq, como ele mesmo expressou em uma entrevista publicada em 1987:

A palavra 'mimo' não era entendida no sentido que eu lhe dava e eu fiquei muito rapidamente prisioneiro de um equívoco que, infelizmente, subsiste ainda hoje [cerca de 30 anos], mas que pouco a pouco se atenua diante da realidade de meu ensino e diante da evolução do teatro do gesto em numerosos países, a partir dos anos sessenta e setenta principalmente. (LECOQ, 1987a, p. 112).

Ao ler os primeiros artigos e entrevistas de Lecoq, publicados no final da década de 1960 e início de 1970, percebe-se esse tipo de conflito. Em entrevista, vinte anos antes, em 1967 (provavelmente o primeiro texto com declarações de Lecoq

SCHEFFLER, Ismael. Jacques Lecoq e a antropologia do gesto de Marcel Jousse.

PÓS:Revista do Programa de Pós-graduação em Artes da EBA/UFMG. v.9, n.17: mai. 2019.

Disponível em <https://eba.ufmg.br/revistapos>

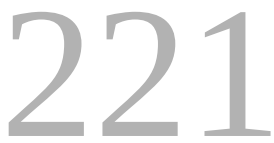


sobre sua pedagogia), a primeira questão proposta foi justamente para esclarecer que tipo de escola era: se de arte dramática ou um curso de mimo. Ao que Lecoq respondeu:

Minha escola não é apenas uma escola de mimo, é uma escola que tende a ser uma verdadeira escola de arte dramática completa, baseada no conhecimento do movimento vivido inicialmente pelo corpo humano em seu gestual econômico; é sem dúvida por que eu falo muito de Movimento que dizem que minha escola é um curso de mimo (PERRET, 1967, p. 55-6).

Em outros textos e entrevistas, percebe-se de forma mais acentuada sua luta para esclarecer sua compreensão de mimo e um combate à forma como o termo era compreendido generalizadamente, como expressou em 1972: "Seguidamente me perguntam: o que você faz em sua escola? Você faz mimo?" E complementou:

Tenho sempre a impressão de que a pessoa que me pergunta isso reduz a escola a um formalismo silencioso. A palavra "mimo" já encerra um limite. Se vê um ator que não fala e que faz gestos estilizados para mostrar objetos que não existem, ou caretas para dar a entender que ele ri ou chora. Então eu respondo que eu não faço mimo, não esse aí (LECOQ, 1972, p. 41).

A questão ainda aparece nos anos de 1980, como expresso no Congresso Internacional de Teatro da Catalunha, em 1985, quando novamente ele afirmou ser necessário esclarecer o termo mimo e enfatizou: “Eu tenho combatido neste sentido desde a criação de minha escola em 1956" (LECOQ, 1985, p. 92).

São diversos os estudos que procuram compreender e definir o mimo para Lecoq, frequentemente articulam comparações com o mimo desenvolvido por Étienne Decroux, apontando diferenças de entendimento do termo e de práticas. ${ }^{5}$ Alguns dos artigos são: The Mime of Jacques Lecoq (ROLFE, 1972); Le mime contemporain (MOUNIN, 1970); livros especializados no tema que dedicam um capítulo para Lecoq, como: Apostles of silence: the modern french mimes (FELNER, 1985); Modern and post-modern mime (LEABHART, 1989); Mimo e teatro nel Novecento (DE MARINIS, 1993); e pesquisas acadêmicas: Du mime a l'art mimique (WEISS, 1972); e Le mouve- 
ment chez Etienne Decroux et Jacques Lecoq (JOUIN, 2007). Além de inúmeros outros pesquisadores que revisam a pedagogia de Lecoq de forma mais abrangente e contemplam o mimo dentre outros aspectos da proposta de ensino.

"Prisioneiro de um equívoco" (LECOQ, 1987a, p. 112) foi o termo utilizado por Lecoq, o que permite depreender que esse aspecto de sua pedagogia foi supervalorizado. O mimo é um dos elementos da pedagogia lecoquiana, presente no curso de formação de atores e no Laboratório de Estudo do Movimento (LEM).

Por tudo isso, a tradução de Le corps poétique para o português, publicada em 2010, torna comprometedora a compreensão da pedagogia de Lecoq no Brasil. Ao traduzir mime como mímica e o verbo mimer como fazer mímica, dá-se margem a compreender a proposta de Lecoq rumo à pantomima e, assim, perpetuar uma visão distorcida ou a inaugurar (para aqueles que tomam contato com a pedagogia com base na leitura / no livro) um equívoco como aquele que comprometeu a compreensão da pedagogia lecoquiana na França desde sua fundação. A tradução de rejeu e rejouer como "reinterpretação" e "reinterpretar" também cria dificuldades. As traduções mais apropriadas seriam os neologismos mais literais: "rejogo" e "rejogar", terminologias também defendidas por Sachs (2013).

\section{As críticas do espetáculo Carnet de Voyage}

Após ser formada a primeira turma de alunos, Lecoq montou uma companhia de teatro com alguns deles e realizou, em 1959, o espetáculo Carnet de Voyage Voyage autour du mime [Caderno de Viagem - Viagem em torno do mimo], que mostra as diferentes possibilidades do mimo, abertas ao teatro e à dança. O espetáculo era composto de diversos quadros e envolvia: coro com máscaras, música concreta, figuração mímica, pantomima branca, número cômico, melodrama coletivo e commedia dell'arte (LECOQ, 2010a).

SCHEFFLER, Ismael. Jacques Lecoq e a antropologia do gesto de Marcel Jousse.

PóS:Revista do Programa de Pós-graduação em Artes da EBA/UFMG. v.9, n.17: mai. 2019.

Disponível em <https://eba.ufmg.br/revistapos>

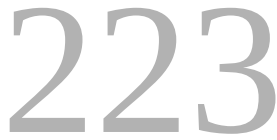


O espetáculo foi apresentado no teatro da Aliança Francesa de Paris, em outubro de 1959. As críticas jornalísticas se referem ao espetáculo como sendo de mimo, realizado por uma companhia de mimo. ${ }^{6}$ Observando o teor das publicações, percebe-se o ponto de referência dos críticos a respeito do mimo.

As críticas, em sua maioria, apresentam vários aspectos negativos e tecem comparações com Decroux, Marcel Marceau (1923-2007) a e Jean-Gaspard Deburau (1776-1846). Um dos aspectos seguidamente criticado foi a utilização da fala em alguns quadros. O crítico Jean-Jacques Gautier, do jornal Le Figaro, ${ }^{7}$ considerou que o espetáculo foi uma sucessão de erros ao introduzir falas, ter gestos ilegíveis, tendo sido marcado pelo amadorismo, um espetáculo pretensioso. Também o crítico P. Marcalerie, do periódico Arts $^{8}{ }^{8}$ utilizou adjetivos semeIhantes, referindo-se ao espetáculo como ingênuo, pretensioso, inacabado, com múltiplos movimentos e ações dispersivas, ilegível, utilizando a fala, intelectualizado.

Já o crítico J. C. Jaubert, do Parisien Libéré, ${ }^{9}$ foi quem demonstrou mais abertura na recepção (apesar de criticar a fala dos atores): “As longas caminhadas feitas pela trupe em Do outro lado da montanha, e em Passagem fazem parte, ao contrário do teatro, do teatro de vanguarda. O coro mudo que atravessa mares, colinas, rios tem uma pureza plástica e uma precisão impressionantes."

Outro texto deve ser somado a esta análise das críticas do espetáculo Carnet de Voyage. Gabriel Cousin escreveu um artigo no qual refletiu sobre as críticas a Lecoq. Em Mime et mouvement avec La Compagnie Jacques Lecoq [Mimo e movimento com a Companhia Jacques Lecoq], ${ }^{10}$ datado de 1960, Cousin rebateu a crítica jornalística parisiense e defendeu o amigo ao afirmar que "Parece que este espetáculo não foi compreendido por toda crítica."

De forma bastante didática e esclarecedora, Cousin lançou uma explicação que demonstra claramente duas compreensões distintas das funções e das técnicas que o termo mimo era empregado.

SCHEFFLER, Ismael. Jacques Lecoq e a antropologia do gesto de Marcel Jousse. PÓS:Revista do Programa de Pós-graduação em Artes da EBA/UFMG. v.9, n.17: mai.. 2019. Disponível em <https://eba.ufmg.br/revistapos>

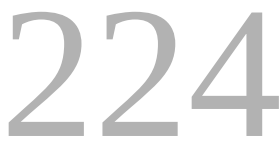


Há dois caminhos principais tomados pela arte do mimo. Um, o mais conhecido do grande público, é aquele que foi ilustrado nos últimos anos por Marcel Marceau. Ele é baseado na ilusão. Desde Deburau, é a tendência mais utilizada pela arte do mimo em sua renovação. $O$ outro, praticamente pouco conhecido, e utilizado pelos mimos da antiguidade, é baseado na transposição. É sobre esse que tem pesquisado, trabalhado Jacques Lecoq. [...] No segundo, a presença do corpo inteiro importa. Não são mais o rosto e as mãos, mas o eixo vertebral e a bacia. Ele é então muito mais sintético e confere maior importância ao ritmo dos gestos. Ele é mais a arte do movimento que da mímica. [...] Ele não está fechado em si mesmo, ele se abre para o 'coração corporal' e para o balé (COUSIN, 1960).

Este pequeno e singular artigo provavelmente é o primeiro texto publicado que propunha esclarecer e definir conceitos sobre o trabalho de Lecoq. Cousin propõe um reparo de enfoque. Quando sustentou que "é mais a arte do movimento que da mímica", procurou utilizar dois termos diferentes (movimento e mímica), mais contrastantes do que o termo mimo, defendendo a proposta de Lecoq como "arte do movimento".

O livro organizado por Lecoq, em 1987, deu ênfase ao gesto em detrimento do mimo, como manifestado no título: Le théâtre du geste - mimes et acteurs [O teatro do gesto - mimos e atores]. ${ }^{11}$

\section{Vocabulário em transição}

Na realização de um mapeamento de publicações de autoria de Jacques Lecoq e de entrevistas que tenha concedido, foi possível identificar algumas a partir de 1967.

Jacques Lecoq: d'abord le mouvement [Jacques Lecoq: primeiramente o movimento] foi publicado na revista Treteaux, em novembro, é assinado por Jean Perret (1967). Perret inicia com uma reflexão sobre a situação do ensino das escolas oficinais de teatro na França, enumerando as poucas existentes e o perfil de formação oferecida. Perret, então, inclui a escola de Lecoq, apontando os principais tópicos do programa e reconhece a filiação de Lecoq a Jacques Copeau e a Charles Dullin. Ele inclui, então, na sequência da publicação, a transcrição de uma entrevista com Lecoq. Nela são discutidos alguns aspectos pedagógicos, assim como ques-

SCHEFFLER, Ismael. Jacques Lecoq e a antropologia do gesto de Marcel Jousse. PóS:Revista do Programa de Pós-graduação em Artes da EBA/UFMG. v.9, n.17: mai. 2019. Disponível em <https://eba.ufmg.br/revistapos>

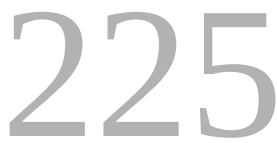


tões consideradas polêmicas, como a da escola ser ou não de mimo, a preparação dos alunos atores para atuarem os mais diversos estilos teatrais após formados, o mercado de trabalho, o preço da escola. Também é tratado sobre o perfil discente e docente da escola.

Em 1967, um curto texto publicado no jornal Atac Informacion anuncia que em dezembro daquele ano Lecoq iria descentralizar sua escola para o Casa da Cultura de Amiens (cidade ao norte de Paris). ${ }^{12}$ Com o título Le mouvement et le théâtre [O movimento e o teatro], Lecoq principia sua refleção sobre o mimo:

Não me atrevo a dizer "O mimo e o teatro" e substituo a palavra "mimo" pela palavra "movimento", com pesar, por medo de ser mau compreendido - isso quanto ao título do artigo [Movimento e teatro].

É assim que a palavra mimo é considerada no teatro francês: como uma doença que assusta os atores e os dançarinos; cada um, em sua ideia, o fixa, o limita em um estilo tipificado e muitas vezes solitário.

É verdade que os mimos mataram o mimo em seus pais naturais, esgotados e cansados. Os Mimos mataram o Mimo, fonte do Teatro e da Dança.

Os mimos deram um rumo ao teatro o colocando diante de um muro que só o virtuose com grande talento pode escalar. Eles conduziram esta arte a um beco sem saída. Esta arte frágil ficou encolhida na anedota, imitou a si mesma e matou em si o que poderia ser uma proposta aberta para o teatro, indo ao encontro dele. (LECOQ, 1967, p. 7).

Nesse sentido, Lecoq também declarou na entrevista: "O mimo me interessa em seu nascimento e não na sua cristalização. Os mimos mataram o mimo por tornálo uma arte fechada que só um virtuose pode sustentar. A extensão do mimo está no teatro ou na dança" (PERRET, 1967, p. 58).

Há nessas declarações uma crítica severa a uma compreensão do mimo como linguagem artística específica e a manifestação de um entendimento mais aberto, tendendo a sinônimo de "movimento", material que pode servir tanto à produção de teatro quanto de dança. Essas declarações também se alinham a Cousin (1960).

SCHEFFLER, Ismael. Jacques Lecoq e a antropologia do gesto de Marcel Jousse. PÓS:Revista do Programa de Pós-graduação em Artes da EBA/UFMG. v.9, n.17: mai. 2019. Disponível em <https://eba.ufmg.br/revistapos>

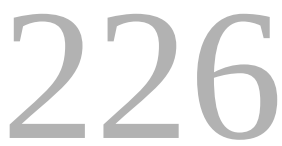


Lecoq distingue o "mimo do fim" [mime de la fin] (a arte do mimo como conhecida, com um repertório de movimentos sistematizados) do "mimo do começo" [mime du début], como define: “O mimo é por excelência uma arte de pesquisa, a profundidade de seu silêncio se acha no princípio de todas as formas de arte" (LECOQ, 1967, p. 7). Usando termos de Marco De Marinis (1993): há o mimo como uma forma de educação e outro como um gênero autônomo e específico.

Lecoq utiliza também o termo fundo mimético comum, referindo-se a um silêncio de fundo no qual se poderia achar o gesto puro, diferente do gesto imitativo (fruto de um silêncio superficial e mutilado). O termo se refere a uma base de apoio, no caso, o silêncio. O jogo silencioso não pretende um caminho de racionalização ou distrações, mas quer percorrer, silencioso um caminho sensível. O mimo, nesse caso, parece estar correlacionado à ideia de improviso e de experimentação.

Outro texto, de 1968, também publicado por ocasião de Lecoq instalar sua escola em novo endereço: no Théâtre de l'Est Parisien. ${ }^{13} \mathrm{Em}$ Du mime au théâtre - L'école Jacques Lecoq s'ouvre au public [Do mimo ao teatro - A Escola Jacques Lecoq se abre ao público], são apresentados diversos aspectos da pedagogia lecoquiana. Lecoq sublinha a importância de uma educação do indivíduo no desenvolvimento de uma consciência de si de maneira sensível antes de uma educação dramática voltada ao jogo teatral. Ele ressalta a importância de aprender a ver, ouvir e observar atentamente o mundo, aprendendo a jogar com a vida. Lecoq argumenta que o olho e o ouvido captam imagens e sons que, uma vez assimilados e compreendidos, contribuem para a riqueza do trabalho do ator que deve ser capaz de transportar tudo isso para os limites do teatro e recriar.

Lecoq acredita na observação científica de ações e estados econômicos do ser humano. Salienta dois eixos: a análise do movimento (com economia: mínimo de esforço para o máximo de rendimento) e a improvisação.

Por meio dela, o aluno começa a identificar as regras do jogo teatral. Lecoq aponta diferentes formas: a improvisação de expressão realista, na realização de ações como um duplo da vida; a improvisação mascarada que contribui para a

SCHEFFLER, Ismael. Jacques Lecoq e a antropologia do gesto de Marcel Jousse. PÓS:Revista do Programa de Pós-graduação em Artes da EBA/UFMG. v.9, n.17: mai.. 2019. Disponível em <https://eba.ufmg.br/revistapos>

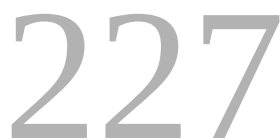


percepção do estado dramático neutro (o ponto comum entre todos os homens, o denominador comum do drama); e a "identificação com o mundo que nos envolve em seus dados elementares e fundamentais (ar, água, fogo...)." (LECOQ, 1968, p. 5). O termo “idenficação” é empregado diversas vezes nesse texto.

Pode-se encontrar referências da prática de exercícios de identificação com os elementos da natureza na Escola do Velho Pombal [Vieux-Colombier], sob a direção de Jacques Copeau, e também n'O Ateliê, de Dullin, isto já na década de 1920 . No entanto, segundo Lucian Stefanesco, em La formation corporelle de l'acteur au XXème siècle - L'École Jacques Lecoq [A formação corporal do ator no século 20 - A Escola Jacques Lecoq], "os exercícios de identificação com os elementos, os vegetais, os animais, remontam a Copeau, e se crermos nos testemunhos dignos de fé, Delsarte ${ }^{14}$ foi o primeiro a pensá-los." (1972, p. 50). ${ }^{15}$

Lecoq, então, toma por base um tipo de exercício herdado de Coupeau-DastéDelsarte. Ele percebe nisso a potência de mimo e o toma como fundamento da formação do ator:

O mimo, bem compreendido, pode ser o fundamento da formação do ator. Este, quando realiza em si a identificação, confunde o gesto e seu drama, e se torna um mimo maior que mantém a fala em suspenso. [...] Mimo e teatro se confundem em um certo nível, o resto é apenas regra do jogo. Uma escola dramática deve ser um lugar privilegiado onde o ensinamento dramático, ministrado seguindo um método e uma pedagogia, proporciona ao aluno uma formação essencial passível de se adaptar a diferentes teatros. (LECOQ, 1968, p. 5).

Nesse contexto, Lecoq afirma que a ação física oferece mais segurança que a expressão sensível, pois a morfologia permite observar a ação. Ele aponta para uma fusão do físico e do sensível.

A primeira publicação mais longa em que são discutidos conceitos e práticas de Lecoq resultou de uma mesa redonda, em 1969, ocorrida na Bienal de Veneza: Ritorno all'espressione fisica dell'attore. Atti della tavola rotonda Internazionale del 19 settembre 1969 [Retorno à expressão física do ator. Ata da mesa redonda internacional de 19 de setembro de 1969] ${ }^{16}$ (RITORNO, 1970). 
Nessa ocasião, Lecoq apontou com clareza seu interesse pedagógico:

Para mim, como professor, o teatro não tem nenhuma importância, nem mesmo o mimo. É o "movimento" que me interessa, o que motiva o teatro, o mimo e outras coisas. Sinto a vida principalmente como um fenômeno dinâmico, quer se trate de uma expressão teatral mimada ou escrita, isso é secundário. É a base que está em jogo e é nesse nível que eu começo com meus alunos, o importante é que todos possam encontrar na essência daquilo que se move e este é um “lugar indefinível" (LECOQ, 1980, p. 201).

Essa declaração se alinha às publicações anteriores. Também pode remeter ao fato de que Lecoq principiou sua formação pelo movimento (educação física e fisioterapia) e foi a partir daí que desenvolveu seu ensino, o que trouxe um diferencial a sua visão sobre teatro.

Este evento foi realizado em um momento de nova aplicação da pedagogia de Lecoq com seu ingresso como docente na Escola Nacional Superior das Belas Artes de Paris - Unidade Pedagógica de Arquitetura n. 6 (UP6), (atualmente Escola Nacional Superior de Arquitetura de Paris La Villette), onde lecionou de 1969 a 1987, formando arquitetos em paralelo a sua escola de teatro. ${ }^{17}$

Assim expresso, ele defendeu uma visão de abertura, não baseada nos princípios do teatro literário nem voltada para essa linguagem artística prioritariamente. Isso pode ajudar a entender como a sua compreensão da pedagogia teatral poderia se articular de forma natural, sem forçar uma aplicação a outros campos do conhecimento ou linguagens artísticas, como a arquitetura.

Em 1969, na mesa redonda de Veneza, Lecoq reafirmou seu interesse de "tocar o fundamento elementar", ressaltando que o mimo não deveria ser em si, isto é, o mimo "não pode viver muito tempo sozinho", pois deveria conduzir ou ao teatro, ou à dança, caso contrário, o mimo poderia cair no virtuosismo. Lecoq defendeu que o importante não era encontrar um gesto comunicativo [expresso], mas encontrar o "gesto de fundo, aquilo que não se vê" (LECOQ, 1980, p. 202), e afirmou que, sob a palavra e o gesto explícito existiria outro gesto, diferente da 
gesticulação (pois ele também poderia ter uma expressão imóvel). Lecoq mesmo disse que não saberia se sua explicação era clara, mas, naquele momento, não saberia dizer de outra forma.

É interessante observar nesses quatro textos que, embora a essência da pedagogia de Lecoq já estivesse delineada, havia uma ausência de termos-chave, empregados posteriormente na pedagogia lecoquiana.

Em janeiro de 1972, Lecoq publicou um artigo, por ocasião da instalação da Escola no Théâtre de la Ville (a escola de Lecoq passou por diferentes lugares antes de se instalar difinitivamente, em 1976, em seu atual endereço). Em L'école Jacques Lecoq (mime-mouvement-théâtre) au Théâtre de la Ville [A Escola Jacques Lecoq (mimo-movimento-teatro) no Teatro da Cidade], Lecoq realiza uma apresentação das propostas de seu curso. ${ }^{18}$ Ele discorre sobre o programa de ensino do primeiro e do segundo ano, incluindo algumas informações gerais trazendo a conceituação.

Esse artigo apresenta maior clareza conceitual e se diferencia dos anteriores, por Lecoq utilizar os termos rejogar [rejouer] e mimar [mimer]:

Para mim, o mimo, como se pode apreendê-lo na escola, é a base de todas as expressões do homem, sejam elas gestuais, construídas, plásticas, sonoras, escritas ou faladas. O mimo que eu chamarei ‘de fundo' é a maior escola do teatro, ela se apoia no movimento. É no gesto sob o gesto, no gesto sob a palavra, no movimento das matérias, dos sons, das cores e das luzes, que a escola encontra suas bases. Nós tomamos conhecimento do que se move pela faculdade que o homem tem de "mimar", isto é, de se identificar com o mundo ao rejogá-lo, com todo o seu ser. É no corpo silencioso do homem, e a partir dele, que se formulam os impulsos da expressão e, em especial, os da expressão dramática, e, mais tarde, os da criação dramática. Esse fogo que eu vejo arde em mim. Eu posso conhecer esse fogo me identificando com ele pelo jogo; eu dou meu fogo ao fogo (LECOQ, 1972, p. 41).

Observa-se os mesmos princípios das publicações anteriores. O que antes era expresso como mimo de princípio, mimo de fundo, identificação ou transposição, aqui aparece em outro vocabulário.

SCHEFFLER, Ismael. Jacques Lecoq e a antropologia do gesto de Marcel Jousse.

PÓS:Revista do Programa de Pós-graduação em Artes da EBA/UFMG. v.9, n.17: mai. 2019.

Disponível em <https://eba.ufmg.br/revistapos>

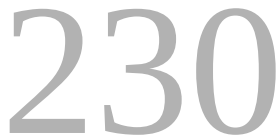


Nesse artigo, Lecoq faz referência ao princípio de sua escola novamente, da observação da vida, destacando agora que ela é revivida pelo rejogo mímico ["revécue par le rejeu mimique"] (LECOQ, 1972). Lecoq ressalta que o mimo é a base de todas as expressões do homem (gestuais, plásticas, construídas, sonoras, escritas ou faladas) e reafirma seu princípio: “O mimo que eu chamo 'de fundo' é a maior escola do teatro, ela se apoia sobre o movimento" (LECOQ, 1972, p. 41).

Esse enriquecimento de vocabulário, que envolve um certo refinamento conceitual, pode ser atribuido ao conhecimento dos estudos do antropólogo Marcel Jousse, cujo livro L'anthropologie du geste foi publicado no ano de 1969. Tomando por base as referidas publicações, minimamente coincide a inexistência de certos termos antes e depois de 1969.

\section{Presença de Jousse nos estudos sobre Lecoq a partir do início dos anos de 1970}

Lucien Stefanesco foi aluno de Lecoq em 1968 e 1969, tendo realizado entrevistas em 1971 e 1972 para a realização de sua tese La formation corporelle de l'acteur au XXe siècle: l'école Jacques Lecoq. Conforme Stefanesco afirmou, Lecoq havia tomado conhecimento do livro L'anthropologie du geste recentemente ["assez récemment"] e havia se entusiasmado, afinal: "Marcel Jousse dava conta de suas intuições latentes, graças a um vocabulário muito mais apropriado que outros" (STEFANESCO, 1972, p. 255). Para este pesquisador, Lecoq “soube orientar [sua pedagogia] em um novo sentido, aquele que Jousse apresenta em $A$ antropologia do gesto" (STEFANESCO, 1972, p. 7). Embora Stefanesco tenha tido essa importante informação, a análise comparativa que realizou entre os conceitos de Jousse e Lecoq foram muito superficiais. ${ }^{19}$

Também de 1972, é a dissertação de mestrado de Willian Weiss: Du mime à l'art mimique [Do mimo à arte mímica]. Weiss dedicou um capítulo a Lecoq e focou sobre a questão do mimo. Ele tomou os estudos de Marcel Jousse publicados em 
L'Anthropologie du geste como referencial teórico para esclarecer alguns conceitos de Lecoq, fundamentando de forma muito rica (embora não tenha afirmado haver influência direta).

Outra importante fonte que demonstra o conhecimento e a relevância dos estudos de Jousse para Lecoq, nesse período, é o memorial de graduação de Krikor Belekian em arquitetura na UP6, de 1972, sob a orientação de Lecoq. Nas referências bibliográficas finais, consta L'anthropologie du geste. Mesmo que Belekian não cite ou se refira aos conceitos de Jousse ao longo de seu estudo, a presença da bibliografia comprova o acesso e relevância dada a obra. ${ }^{20}$

Nesse mesmo ano, Lecoq foi procurado pelo antropólogo estadunidense Laurence Wylie (1909-1996), que estava interessado em seu trabalho. Ele se interessava pelo estudo de gestos e da comunicação não verbal como uma forma de entender uma cultura estrangeira (UN ORIGINAL, 2000), tendo o objetivo de compreender as diferenças entre os franceses e os americanos. Wyllie teve contato com o trabalho de Lecoq quando este esteve em Harvard, em 1970. Já desenvolvendo suas pesquisas sobre o gesto, Wylie decidiu passar dez meses na escola de Lecoq, em 1972-1973, onde foi aluno, aos 63 anos, com os demais jovens estudantes da escola.

Em função dessa experiência, Wylie escreveu o artigo À l'école Lecoq j'ai découvert mon propre clown [Na Escola Lecoq, eu descobri meu próprio palhaço], publicado em 1973, no qual incluiu uma longa citação de Marcel Jousse, indicando alguma relação, sem contudo aprofundar a análise. ${ }^{21}$

Marcel Jousse é referido por Lecoq no livro Le théâtre du geste (1987a), no artigo L'imitation: du mimétisme au mimisme [A imitação: do mimetismo ao mimismo], no qual Lecoq expôs em breves linhas esses aspectos-chave da antropologia de Jousse, muito embora não tenha assumido qualquer relação se Jousse o havia influenciado ou se suas pesquisas tinham, sob seu ponto de vista, correlações. O título do artigo remete diretamente a Jousse, pois a discussão sobre o tema estava no centro de suas pesquisas. A diferenciação entre mimismo, mimetismo 
e imitação é apresentada por Jousse em L'anthropologie du geste (2008) e foi tratada em diversas conferências, como a intitulada Mimétisme et mimisme, apresentada por Jousse em 28 de novembro de 1932, na École d'Anthropologie (JOUSSE, 2003).

Também em Le corps poétique (1997), Lecoq diferencia mimetismo e mimismo: “O mimetismo é uma representação da forma, e mimismo é a busca da dinâmica interna do sentido" (LECOQ, 2010, p. 51). Em outras palavras: "Não se trata de imitar [a forma], mas de sentir através de um sentimento interior" (LECOQ apud DE MARINIS, 1993, p. 256).

Jousse é reconhecido ou citado posteriormente por outros pesquisadores de Jacques Lecoq, a saber: Felner (1985); Frost e Yarrow (1990); Merlant (2004); Freixe (2014), mas, em geral, de forma breve, por vezes não passando de uma menção sem estreitar a análise.

O pesquisador italiano Marco De Marinis, em Mimo e teatro nel Novecento (1993), afirma claramente que Lecoq empresta os termos mimismo e rejeu de Jousse e ressalta que seu estudo antropológico filosófico o ajudou "a distinguir mais claramente entre um mimo em sentido estrito e um mimo em sentido amplo" 22 (DE MARINIS, 1993, p. 256).

De forma significativa, a brasileira Cláudia Sachs dedicou-se a tecer correlações entre Lecoq e Jousse, em sua tese (SACHS, 2013), e no capítulo Bachelard, Jousse and Lecoq, do livro The Routledge Companion to Jacques Lecoq (SACHS, 2016). Ela revisa conceitos-chave de Jousse, estabelece relações com Lecoq e com a imaginação material de Gaston Bachelard.

Jousse é apontado como um teórico importante para a compreensão da pedagogia lecoquiana, como salientou em entrevista sua filha Pascale Lecoq (2011), atual diretora da escola de teatro e do Laboratório de Estudo do Movimento (LEM), tendo sido indicado como leitura por Belekian em aula do LEM. ${ }^{23}$ 


\section{Marcel Jousse}

Marcel Jousse (1886-1961) foi padre jesuíta e antropólogo francês. Publicou pouco durante sua vida. Seu primeiro texto publicado, em 1924, correspondia ao resultado de vinte anos de pesquisas: Le style oral rythmique et mnémotecnique chez les verbo-moteurs [O estilo oral rítmico e mnemotécnico nos verbo-motores]. ${ }^{24}$ Sua produção intelectual como antropólogo desenvolveu-se basicamente na transmissão oral, escrevendo raramente, como exposto no prefácio de L'Anthropologie du geste: "O que ele teme, ao escrever cedo demais, é fixar ou enrijecer prematuramente sua pesquisa. Ele quer se guardar disponível, aberto, receptivo" (JOUSSE, 2008, p. 15).

Jousse era um crítico do ensino livresco, defendia por meio de suas pesquisas uma determinada concepção de ensino baseada nas experiências práticas. MarieFrançoise Fromont (1978), em L'enfant mimeur, l'anthropologie de Marcel Jousse et la pédagogie [A criança mimante, a antropologia de Marcel Jousse e a pedagogia], apresentou os principais aspectos da concepção de Jousse sobre a educação. Em diversos aspectos, sua concepção coincide com os principais aspectos da éducation nouvelle (Escola Nova), especialmente no que concerne ao ponto de partida do processo de aprendizado: a relação direta com mundo, experimentando-o para adquirir o verdadeiro saber. Também a pedagogia de Lecoq tem fundamento em inúmeros pontos coincidentes aos pricípios englobados pela éducation nouvelle.

A infância foi um dos campos de observação e estudo de Jousse, que percebeu a característica inerente a todas as crianças: o mimismo. Relacionando a outros campos, como civilizações arcaicas e povos indígenas americanos, entre outros, ele desenvolveu o conceito sobre o qual construiu a base de suas pesquisas: "O anthropos é um animal interacionalmente mimante" (JOUSSE, 2008, p. 55).

SCHEFFLER, Ismael. Jacques Lecoq e a antropologia do gesto de Marcel Jousse.

PÓS:Revista do Programa de Pós-graduação em Artes da EBA/UFMG. v.9, n.17: mai.. 2019. Disponível em <https://eba.ufmg.br/revistapos>

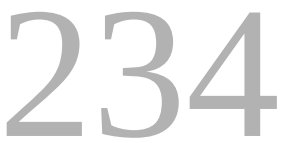


As pesquisas de Jousse envolviam aspectos de fisiologia, neurologia, ritmologia, fonética experimental, linguística, psicologia, etnologia, religiões e pedagogia seus estudos em antropologia corresponderam a um período de estabelecimento dos campos dessa ciência (JOUSSE, 2008), tornando-o um precursor de pesquisas transdisciplinares.

Jousse, que cresceu em zona rural e manteve essa ligação com a natureza como referência em seus estudos, veio a Paris em 1922. Foi aluno de Henri Bergsone de diversos professores: Pierre Janet, Georges Dumas, Henri Delacroix, JeanPierre Rousselot, Antoine Meillet e Marcel Mauss (JOUSSE, 2008). Fromont (1978) aponta diversos aspectos correspondentes entre a filosofia de Bergson e os estudos de Jousse.

Jousse buscava as leis antropológicas universais, especialmente sobre a expressão humana; uma compreensão do que é universal, permanente, inerente ao ser humano. Foi baseado na observação do mundo objetivo que Jousse elaborou sua ciência - não por meio de estudos em livros, mas por meio de vários laboratórios experimentais e constatações, observando o ser humano.

Seu método de trabalho remete a Lecoq em alguns aspectos: uma pesquisa viva, objetiva, que realiza constatações da vida prática do homem e da natureza (e não pela escrita). A diferença maior entre esses talvez recaia sobre a sistematização do conhecimento: ambos publicaram pouco em vida, ambos partilharam suas constatações em suas aulas, mas Jousse teve a preocupação em garantir o registro sistemático de sua transmissão oral. Suas aulas e conferências foram registradas por um estenotipista profissional durante 30 anos, material que posteriormente foi transcrito para perpetuar suas reflexões.

Jousse deu diversas conferências livres e aulas em diferentes instituições francesas, registros que compõem um corpus teórico, organizado cronologicamente e por instituição, seu período mais intenso de produção entre 1931 e 1957. Jousse partilhou suas pesquisas e conceitos na Universidade Sorbonne (de 1931 a 1956); na École des Hautes Études [Escola de Altos Estudos] (de 1933 a 1945), na

SCHEFFLER, Ismael. Jacques Lecoq e a antropologia do gesto de Marcel Jousse. PóS:Revista do Programa de Pós-graduação em Artes da EBA/UFMG. v.9, n.17: mai. 2019. Disponível em <https://eba.ufmg.br/revistapos>

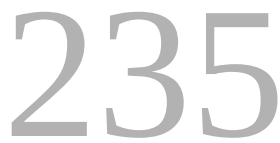


École d'Anthropologie [Escola de Antropologia] (de 1932 a 1951); no Laboratoire de Rythmo-Pédagogie [Laboratório de Ritmo-pedagogia] (de 1933 a 1939), criado por ele, e na École d'Anthropolo-Biologie [Escola de Antropo-biologia] (1948). Esse material, contendo cerca de vinte mil páginas transcritas, recebeu o título Les cours de Marcel Jousse [As aulas de Marcel Jousse] e foi inicialmente distribuido em CD-room, está também disponível na página da Association Marcel Jousse na internet. ${ }^{25}$

Jousse faleceu em 1961. Em 1968, foi fundada a Association Marcel Jousse ${ }^{26}$ com a finalidade de difundir e preservar os ensinamentos do antropólogo. A publicação do livro L'anthropologie du geste, obra chave de suas teorias, foi publicada por seus discípulos, em 1969. As outras duas obras publicadas foram La manducation de la parole [A mastigação da palavra] (1975) e Le parlant, la parole et le souffle [O falante, a palavra e a respiração] (1978), todas inéditas em português.

O preço dessa opção (reservar o partilhamento de suas pesquisas de forma quase unicamente oral) legou Jousse (como também de certa forma ocorreu com Lecoq) a um certo desconhecimento no meio acadêmico. Jousse e Lecoq não acreditavam que o verdadeiro conhecimento pudesse se dar de forma intermediada pelo papel, fora do contato direto da vivência. Sem deixar muitos registros, tornam árduas as pesquisas posteriores e mesmo a difusão de suas ideias e pesquisas.

\section{Terminologias de Jousse}

Jousse estabeleceu um vocabulário próprio adotando novos termos para explicar seus estudos, como salientado no prefácio de L'Anthropologie du geste: "A linguagem corrente só Ihe oferecia termos cujo sentido é fixado pelo uso social. Ele precisava então forjar seu instrumental de expressão e criar para si um vocabulário novo, preciso, algébrico na necessidade, abrangendo os fatos observados" (JOUSSE, 2008, p. 28). 
Diferentemente de Lecoq, que trabalhou durante anos para esclarecer seus conceitos, utilizando termos já estabelecidos (especialmente ao termo mime), Jousse criou um vocabulário próprio, tomando alguns termos como base. Entre eles, o termo mimismo [mimisme] teve espaço central, escolhido como o que melhor expressava o sentido.

O mimetismo, esclareceu Jousse (1932), é um termo da biologia que corresponde à característica de certos seres vivos que, quer pela cor ou pela forma, tendem a se conformar ao ambiente em que vivem. A imitação corresponde a um ato voluntário e consciente de realizar algo, tornando-se parecido a algo ou alguém. Por fim, o mimismo, foi definido por Jousse (1932), como a capacidade instintiva e inconsciente que o homem tem de reproduzir atitudes, ritmos e movimentos de coisas e seres. Jousse exemplificou isso com uma corrida de cavalos, na qual, em determinado momento, o público já "não é mais" público, mas manifesta a energia dos cavalos que vê diante de si, "se assemelhando" aos cavalos que veem. Essa capacidade pode se tornar consciente e com ela se pode jogar.

Semelhante a Jousse, Lecoq defendeu que o ato de mimar é um ato da infância: a criança mima o mundo como uma forma de conhecê-lo e de se preparar para vida (LECOQ, 1997, p. 21). Jousse afirmou que o mimismo está completamente presente na infância, que a criança brinca com o corpo todo, sem fragmentações, em um empenho natural. Ele também observou que a criança tende a rejogar aquilo que é mais característico (o essencial). Quando Lecoq definiu “corps mimeur" [corpo mimante], no documentário Les deux voyages (1999), ele justamente se referiu ao "corpo que pode tomar as dinâmicas que o rodeiam, o mundo que o rodeia, como uma criança. Todas as crianças mimam [...]."

Jousse definiu o mimismo como tendo duas fases: a intussuscepção [intussusception] (intus = movimento que leva para o interior de si mesmo, para dentro; suscipio/ suscipere $=$ receber, colher, reunir). O homem registra tudo o que o rodeia, ou o que o rodeia se registra nele, como uma argila que recebe uma impressão (FROMONT, 1978; JOUSSE, 2008). A segunda fase é o rejeu: o que é registrado tende a ser reproduzido, exprimido, refeito, "rejogado", "rebrincado". 
Com o termo mimisme, Jousse criou toda uma família de termos. Ele passou a se referir a uma antropologia mimismológica [anthropologie mimismelogique]. Determinou o mimème, que corresponde àquilo que resulta do processo do mimismo, ou seja: o homem recebe em si impressões do mundo que reverberam, que ressoam nele, que são jogadas e apreendidas pelos diferentes sentidos. $O$ homem, então, rejoga, manifestando em gestos os aspectos mais característicos isto é, o mimême [mimème]. Todo rejogo é gestual.

Jousse ressaltou que não há nada de metafísico nesse processo, que é algo quase material, pois o homem não pode se exprimir para si ou para os outros sem ser por mimêmes gestuais. Essas primeiras expressões constituídas pelos mimêmes não formam uma linguagem, mas uma mimagem [mimage]. Segundo Jousse, é graças a mimagem que funciona o pensamento e a memória, o que, por sua vez, conduz a questão da construção do conhecimento. "O homem só conhece o que ele recebe nele mesmo e o que ele rejoga. É o mecanismo do Conhecimento por nossos gestos de rejogo. Nós não poderemos jamais conhecer o que é totalmente fora de nós. Nós não podemos conhecer além do que nos intussuscepcionou mais ou menos perfeitamente" (JOUSSE, 2008, p. 55).

Lecoq utilizava o termo "fundo poético comum" ou "depósito poético comum", que por vezes remete a um sentido afim a Jousse. Em O corpo poético, Lecoq se referia à vida essencializada:

Trata-se de uma dimensão abstrata, feita de espaços, de luzes, de cores, de matérias, de sons, que se encontram em cada um de nós. Esses elementos estão depositados em nós, a partir de nossas diversas experiências, de nossas sensações, de tudo aquilo que vimos, escutamos, tocamos, apreciamos. Tudo isso fica em nosso corpo e constitui o fundo comum a partir do qual surgirão impulsos, desejos de criação. É preciso então, em meu processo pedagógico, atingir esse fundo poético comum, para não ficar na vida tal qual ela é, ou tal qual ela surge (LECOQ, 2010a, p. 82).

No documentário Les deux voyages (1999), esses conceitos se ampliam e se aproximam da compreensão de mimagem de Jousse:

SCHEFFLER, Ismael. Jacques Lecoq e a antropologia do gesto de Marcel Jousse.

PÓS:Revista do Programa de Pós-graduação em Artes da EBA/UFMG. v.9, n.17: mai. 2019. Disponível em <https://eba.ufmg.br/revistapos>

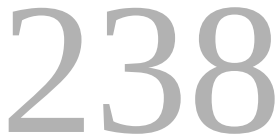


[...] a um certo ponto, criamos uma coisa comum a todos os indivíduos. Uma escola onde há muitas nacionalidades diferentes, quando as pessoas reagem juntos a noção de justeza, é muito importante. Qual seja a cultura ou as idades, uma coisa comum nos reúne. Portanto, no fundo, nos assemelhamos todos, juntamos-nos num 'fundo poético comum'. É muito importante, porque geralmente, na educação, tentamos dar ao indivíduo as próprias origens. Tu és tu, não outro. Eles são felizes de ser eles mesmos. Devemos ter um fator comum e nos dizer: "somos todos iguais". E se somos diferentes, veremos. É importante a noção de 'fundo poético comum'. A palavra poética serve para mostrar que há coisas que não podemos definir e que só a poesia pode definir, o que está entre as palavras, o que é invisível.

Nessa declaração, Lecoq referiu-se à percepção de elementos comuns a todos. Essa percepção cria, de certa forma, uma espécie de repertório comum. É por conta da percepção desse contexto, potente em poesia, que uma espécie de "linguagem", que na realidade é uma mimagem, vai se estabelecendo e passa a ter um "entendimento" comum. Se é dito: "a dimensão do espaço do paladar tem relação com a dinâmica do vermelho", passa-se a lidar com uma mimagem comum que não é nem simbólica, nem propriamente subjetiva. Não é um código, pois não existe uma "convenção" objetivamente instituída. Não se trata de uma forma, mas de dinâmicas, não algo fixado, mas algo fluído.

Não definir os movimentos (como se move a cor violeta ou como se move um terreno rochoso, por exemplo) é defendido com rigor na pedagogia lecoquiana, pois isso eliminaria a etapa exploratória, o desenvolvimento da capacidade perceptiva e o exercício de observação e elaboração das permanências pelas constatações (apesar das diferenças).

Não definir pode encontrar um apoio teórico no argumento de Jousse: “Cada indivíduo difere como intussuscepção. Depois que a intussuscepção se jogou e rejogou em nós, há a conservação pessoal dos rejogos. Esta conservação, vitalmente pessoal, depende da riqueza das intussuscepções e da força da personalidade, pois nós não somos todos iguais" (JOUSSE, 2008, p. 55).

SCHEFFLER, Ismael. Jacques Lecoq e a antropologia do gesto de Marcel Jousse.

PÓS:Revista do Programa de Pós-graduação em Artes da EBA/UFMG. v.9, n.17: mai. 2019.

Disponível em <https://eba.ufmg.br/revistapos>

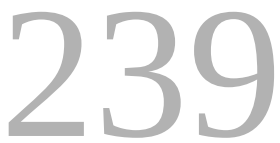


Em outras palavras, sensibilidades diferentes recebem e percebem as impressões do mundo de maneiras diferentes, em distintos aspectos que são diferentemente manifestadas, mimadas. Se o que é "registrado" é diferente, também é a sua manifestação (mimême). O que resta, o que é conservado, também difere. Logo, não há sentido se imposto às outras pessoas. Por isso, os elementos do fundo poético podem ter aspectos comuns (dinâmicas), mas não absolutos em gestos / formas fixadas.

Lecoq afirmou que se trata de algo adquirido pelas experiências (como Jousse se referiu) e o processo de conscientização se dá por constatações feitas observando as pessoas rejogarem. Esse fundo ou depósito é individual, mas por meio de um processo de pesquisa em grupo pode-se reconhecer dinâmicas recorrentes e perceber aspectos comuns, mesmo havendo diferenças. Como pesquisa coletiva, resulta numa compreensão coletiva de permanências.

Para Jousse, tudo no universo interage com o ser humano, imprime [im-pressão], e as diferentes interações são expressadas [ex-pressão] por um mimême que recebe, então, denominações diferentes no vocabulário joussiano: mimoplastismo [mimoplastisme] (é o rejeu com argila, com a forma plástica), mimografismo [mimographisme] (rejeu pelo desenho, pelo grafismo), mimograma [mimogramme] (rejeu por grafismos como chinês e hierógrifos egípcios, escritas antigas que são desenhos de gestos), mimodrama [mimodrame] (rejeu pelo corpo inteiro), fonomimismo [phonomimisme] (rejeu pelo gesto da vocalização), entre outros termos.

A amplitude do mimo já estava presente em Lecoq em 1967: “O mimo é, por excelência, uma arte de pesquisa, a profundidade de seu silêncio está no início de todas as formas de arte. É nesse fundo mimético comum que o artista prepara a escolha de seus impulsos para as diversas formas de expressão." (LECOQ, 1967, p. 7). Conforme De Marinis: “essa concepção ampliada e primária de mimo como (uma das formas possíveis do) mimetismo permite que Lecoq natural e rapidamente supere a contraposição gesto / palavra, teatro do corpo / teatro 
verbal, mimo / ator, baseada na concepção restrita." (1993, p. 257). Esse aspecto colocava Lecoq em uma condição de abertura e deu-lhe a possibilidade de experimentar seus princípios na escola de arquitetura.

Em Le corps poétique, publicado 30 anos depois dessa declaração, ele defendeu a existência de um "mimo escondido" que se encontra em todas as artes. Para ele, todo verdadeiro artista é um mimo, pois, ao pintar um quadro, o pintor antes "essencializou" em si, para o gesto surgir depois. Lecoq considerava que o "mimo" feito por pintores e escultores faz parte do mesmo fenômeno do mimo do teatro: "um mimo imerso faz nascer criações muito diversas, em todas as artes." (LECOQ, 1997, p. 33). É pensando assim que ele mesmo afirmou: "eis por que pude passar do ensino do teatro ao da arquitetura, inventando os 'arquitetosmimantes'." (LECOQ, 1997, p. 34).

Acredito que o entendimento de Jousse que aponta a igualdade dos diferentes gestos, seja corporal, plástico, gráfico ou sonoro, tenha alimentado ainda mais as pesquisas de Lecoq. Além do mimo de identificação corporal dos movimentos da vida (dos movimentos da natureza, das matérias, dos elementos, etc.) (LECOQ, 1968), o trabalho na Escola de Arquitetura e, posteriormente, no Laboratório de Estudo do Movimento (LEM), deram conjuntura para Lecoq explorar outras formas de mimêmes, além do mimodrama, como a escultura, a pintura e o desenho.

Lecoq começou a trabalhar na UP6 no mesmo ano da publicação de L'anthropologie du geste, coincidindo seu ingresso em um novo campo (formação de arquitetos) com um suporte conceitual (Jousse) que ampliava o entendimento do gesto corporal. Ali a atividade manual encontra espaço e é tomada como equivalente ao movimento corporal. Esse princípio de Jousse permite entender com mais facilidade a prática desenvolvida por Lecoq de "apreender pela sensibilidade" as "impressões" que as arquiteturas provocam no ser humano, questões exploradas no LEM e que aparecem no artigo Le corps et son image [O corpo e sua imagem] (LECOQ, 1970). 
Lecoq buscava não um mimo que se voltasse à constituição de forma, mas um que vislumbrasse dinâmicas, que envolvesse o ritmo, o espaço e a força (na relação do puxar e do empurrar) (LES DEUX VOYAGES, 2008), e isso Lecoq chamou de mimodinâmica [mimedinamique].

O termo mimodinâmica se tornou tão importante para Lecoq que ele o definiu como uma pedagogia:

Gostaria de indicar, enfim, como a pedagogia mimodinâmica poderia ser útil em muitos domínios da aprendizagem além do teatro, seja em diferentes artes ou em outras disciplinas do conhecimento. Aquilo que realizei na formação de arquitetos, não para que se tornassem atores, mas para que construíssem melhor, respeitando os movimentos do corpo humano no espaço, pode ser vislumbrado do mesmo modo por outras artes: a música, as artes plásticas esboçamos o trabalho neste sentido - e também a literatura, a dança, etc. Essa postura pedagógica pode ser adaptada a qualquer educação artística: comprometer o corpo mímico [corps mimeur, corpo mimante] para o reconhecimento do real permite a cada um incorporar o mundo que o circunda antes de pintá-lo, de escrevê-lo, de cantá-lo, de dançá-lo... As formas propostas seriam, então, sem dúvida, mais sentidas e menos cerebrais (LECOQ, 2010a, p. 235).

A mimodinâmica, por vezes referida como método de transferências, não é uma expressão intelectualizada, mas não corresponde de forma alguma a um procedimento fora da consciência. Mimar para Lecoq é, antes de tudo, revelar a dinâmica (da matéria, da forma, do poema).

\section{Vinculações de Lecoq com a Associação Marcel Jousse}

Alain Mazas (1935-), membro da Associação Marcel Jousse, foi aluno do LEM na sessão de 1979-1980 (provavelmente a terceira turma). Mazas se aproximou da Associação em 1974, ligado à atividade de memorização dos Evangelhos, baseado nas propostas do antropólogo e padre jesuíta Marcel Jousse. ${ }^{27}$

Mazas relatou em entrevista (2012) que ouviu falar de Lecoq pela primeira vez por meio de Gabrielle Baron (1895-1986). Baron foi colaboradora e secretária de Jousse por muitos anos, e escolhida por ele como a herdeira de seus escritos.

SCHEFFLER, Ismael. Jacques Lecoq e a antropologia do gesto de Marcel Jousse.

PÓS:Revista do Programa de Pós-graduação em Artes da EBA/UFMG. v.9, n.17: mai. 2019.

Disponível em <https://eba.ufmg.br/revistapos>

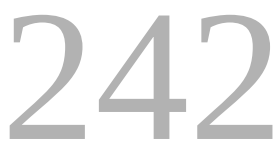


Baron publicou, em 1965, a biografia Marcel Jousse, introduction à sa vie et à son oeuvre [Marcel Jousse, introdução a sua vida e sua obra] (republicada como Mémoire vivante: vie et oeuvre de Marcel Jousse [Memória viva: vida e obra de Marcel Jousse]). Foi graças a ela que os documentos estenografados foram transcritos e disponibilizados como Les cours de Marcel Jousse.

Conforme Christophe Merlant, em seu artigo L'École Lecoq: des mouvements de la vie à la création vivante [A Escola Lecoq: dos movimentos da vida à criação viva] (2004), elaborado com base em entrevistas concedidas por Lecoq em 1998, este não conheceu pessoalmente Marcel Jousse, mas "a abertura a seus textos e seu pensamento se aprofundou em encontros com Gabriele Baron" (MERLANT, 2004, p. 65). Segundo Mazas, Baron foi procurada por Lecoq que estava interessado pelas pesquisas de Jousse:

Ele [Lecoq] ia vê-la sem dúvida para se informar, para se esclarecer, pois além de L'anthropologie du geste, ela tinha publicado Mémoire vivante que é uma biografia. Ele ia vê-la, mas o que eles conversaram, eu não sei, nem qual foi o resultado de sua visita. E foi ela que me deu a indicação. Foi por ela e pela Fundação Jousse que eu ouvi falar de Lecoq e que fui lá, por que eu me disse que se um artista tinha sido a este ponto tocado por Jousse, isso valeria uma olhada para conhecer o que ele faz. Se ele se sentia de acordo com o pensamento de Jousse, então valeria a pena ver o que ele fazia (MAZAS, 2012).

Alain Mazas, que na época fazia sua formação como paisagista, inscreveu-se no LEM, que estava prestes a começar uma nova turma. Segundo Mazas, o LEM representou uma experiência importante em sua formação. Sobre essa época ele relembrou:

Então: descoberta, descoberta, descoberta. A princípio, eu não fazia realmente a ligação entre o LEM e Marcel Jousse e depois, um belo dia, eu compreendi quando compreendi o gesto do gesto. Era a grande descoberta de Lecoq, o gesto sob o gesto e ali eu me disse: "bem, está aí! É isso!" Ele descobriu com sua prática de artista o que Jousse tinha descoberto quando ele falava do "mimême". O mimismo produz em nós os mimêmes que correspondem ao que eu acredito compreender no "gesto sob o gesto" de Lecoq. Nós somos "complexos de mimêmes" para Jousse e para Lecoq, nós somos penso eu -, "complexos de gestos sob os gestos" que, um dia, vão sair, vão se exprimir ou, ao contrário, vão ser reprimidos. Eu creio

SCHEFFLER, Ismael. Jacques Lecoq e a antropologia do gesto de Marcel Jousse.

PóS:Revista do Programa de Pós-graduação em Artes da EBA/UFMG. v.9, n.17: mai. 2019.

Disponível em <https://eba.ufmg.br/revistapos>

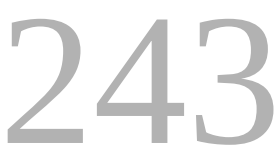


que é esta história de gesto sob o gesto que me pareceu o mais forte para Lecoq. Certamente, havia todas as improvisações que fazíamos junto e aliás, isso me trouxe muitas questões (MAZAS, 2012).

Em 1986, a Fundação Marcel Jousse organizou, com o Centre Sèvres com o apoio da Fondation de Montcheuil, o evento Marcel Jousse: du geste à la parole - Colloque public pour le Centenaire [Marcel Jousse: do gesto a palavra - Colóquio público pelo Centenário (de nascimento de Jousse)], em 21 e 22 de novembro. Jacques Lecoq participou desse evento e realizou uma conferência demonstração com o título: Le geste sous le geste [O gesto sob o gesto]. Alain Mazas assistiu à apresentação de Lecoq, mas não soube informar quem teria realizado o convite. A conferência demonstração foi publicada, em 1987, nos anais do evento ${ }^{28}$ (LECOQ, 1987b).

O texto publicado é subtitulado: Présentation par Jean Perret [Apresentação por Jean Perret]. O texto na realidade é apresentado na voz de Perret (embora Lecoq é que seja creditado), e dá a entender que, enquanto Lecoq realizava as demonstrações, Perret realizava a leitura do texto ("Vemos agora Jacques Lecoq jogar sob a 'máscara neutra'" - p. 57). No texto, são citadas frases de Lecoq em alguns momentos em terceira pessoa ("ele nos dirá: [...]"; “ele nos explica: [...]").

Perret principiou o texto contextualizando o momento:

Rendendo homenagem a Marcel Jousse cujo livro L'anthropologie $d u$ geste o marcou profundamente, e à senhorita Baron, que foi de certa forma 'propagandista', Jacques Lecoq fez questão, desde o princípio, de precisar sua proposta, chamando sua demonstração 'O gesto sob o gesto', isto é, 'o gesto tal qual ele é visto e o que se passa sob o gesto...'; quando entramos numa outra dimensão do movimento, quando o ritmo, a respiração, o silêncio ou a sonoridade mudam ou derivam, quando chegamos a captar a essência. Da mesma forma para Jousse, quando ele detecta sob o gesto, a respiração do espírito, a palavra mesma e o símbolo e todo esse lado de 'espontaneidade mímica' do homem, transformado, acrescentará Jacques Lecoq, pela imagem que ele vê (LECOQ, 1987b, p. 55).

A demonstração descrita no texto refere-se a diversos aspectos da pedagogia de Lecoq: os três movimentos elementares apontados por Lecoq - ondulação (movimento de locomoção); movimento de emoção (também referido como ondulação invertida (LECOQ, 2010a)); e eclosão (movimento de equilíbrio); a marcha e os

SCHEFFLER, Ismael. Jacques Lecoq e a antropologia do gesto de Marcel Jousse.

PÓS:Revista do Programa de Pós-graduação em Artes da EBA/UFMG. v.9, n.17: mai. 2019.

Disponível em <https://eba.ufmg.br/revistapos>

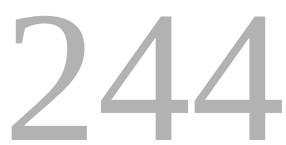


andares; sequências de movimentos do gondoleiro e o lançamento de disco, demonstrando com amplitudes diferentes dos gestos; a máscara neutra e os movimentos do fogo e do óleo. A demonstração tem um mesmo padrão do programa geral desenvolvido no ensino da escola, sem problematizar, discutir ou referenciar os estudos e conceitos de Jousse para além do que a citação acima refere.

Foi por meio dessas demonstrações que Lecoq procurou evidenciar "o gesto sob o gesto", como foi esclarecido com o exemplo do fogo:

\begin{abstract}
Escutemos ainda e olhemos: Jacques Lecoq vai mimar o fogo e ele explica: “Eu devo imaginar fazer o fogo viver em mim, não olhar a periferia do fogo, mas olhar o centro do fogo, se há chamas que me tomam, isto é algo a mais... E percebo assim que há uma analogia muito grande entre estes ritmos (do fogo) e outra coisa, interna... E neste interior, eu vou achar o medo, a angústia e, paradoxalmente, o frio. Uma oposição... eu procuro o que existe na profundidade... Uma relação dramática é estabelecida..." (LECOQ, 1987b, p. 57).
\end{abstract}

Em entrevista, Mazas disse desconhecer outra publicação ou colaboração entre Lecoq e a Associação. Ao que parece, não se estabeleceu um vínculo maior de Lecoq com a Associação Marcel Jousse: “Jacques Lecoq, na Associação Jousse, é finalmente muito pouco conhecido. Eu creio que isto [o texto do colóquio] é a única coisa que existe" (MAZAS, 2012).

Na página da internet dedicada a Marcel Jousse, no tópico Jousse vu, entendu, lu par des personnalités [Jousse visto, ouvido, lido por personalidades], são indicados "ecos" suscitados pelo antropólogo, salientando que pesquisas complementares são necessárias para medir as influências. Sobre Lecoq, é mencionado:

Jacques Lecoq (1921-1999) fez sem cessar referência ao livro L'anthropologie du geste em sua escola de Mimo, Movimento, Teatro. Ele encontrou no pensamento de Jousse um "revelador extraordinário de sua própria pesquisa e de sua experiência" (como ele testemunhou em uma reunião da Fundação Marcel Jousse, em 30 de abril de 1974). ${ }^{29}$

SCHEFFLER, Ismael. Jacques Lecoq e a antropologia do gesto de Marcel Jousse.

PóS:Revista do Programa de Pós-graduação em Artes da EBA/UFMG. v.9, n.17: mai. 2019.

Disponível em <https://eba.ufmg.br/revistapos>

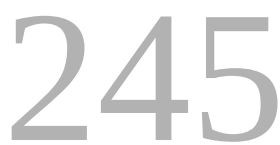




\section{Considerações finais}

Semelhantemente a Mazas (2012), penso que seja difícil saber exatamente quanto Jousse pode ter influenciado Lecoq. Mazas disse crer que Lecoq já tinha desenvolvido por outros caminhos uma pesquisa paralela e que o encontro com a publicação de L'anthropologie du geste teria provocado um sentimento de identificação.

Conforme referido por Stefanesco (1972), acredito que a pesquisa joussiana tenha enriquecido a pedagogia de Lecoq, dando-Ihe um vocabulário mais preciso, como procurei comprovar, respaldando sua pesquisa intuitiva. Lecoq já trabaIhava seguindo a improvisação de identificação com elementos e fenômenos naturais (herdados de Copeau-Dullin-Delsarte), mas com base em Jousse encontrou uma terminologia que permitiu expressar com mais clareza alguns aspectos de sua pedagogia em relação ao mimo. Também Freixe (2014), ressalta que, embora não seja uma inovação de Lecoq, recebeu dele coerência, aporte intelectual e progressão pedagógica remarcável. Lembremos que o rejogo / mimo é apenas um dos elementos da proposta de Lecoq, e este alinhado com outros temas (como a análise do movimento, a máscara neutra, etc.).

No meu entender, a partir dos escritos analisados no artigo, não há uma mudança significativa nas atividades pedagógicas propostas por Lecoq aos alunos atores (antes e depois de 1969), pois ele permaneceu com a mesma maneira de trabalhar com a improvisação / jogo dramático / mimo / rejogo. Também acredito que o conhecimento das pesquisas de Jousse tenha afirmando Lecoq em relação à percepção de que o mesmo método poderia ser aplicado a outras formas de expressão que não apenas a corporal, fomentando seu ensino na Escola de Arquitetura e no que veio a ser o LEM.

Alguns aspectos da pedagogia lecoquiana podem parecer um pouco abstratos ou subjetivos. Acredito que o estudo de Jousse ajude a perceber que, embora dotado de elementos intuitivos, o mimo, segundo Lecoq, está pautado na capacidade de

SCHEFFLER, Ismael. Jacques Lecoq e a antropologia do gesto de Marcel Jousse. PÓS:Revista do Programa de Pós-graduação em Artes da EBA/UFMG. v.9, n.17: mai.. 2019. Disponível em <https://eba.ufmg.br/revistapos>

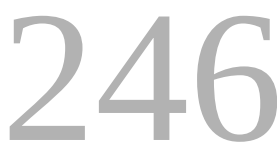


observação objetiva, no desenvolvimento da habilidade consciente de transposição por diferentes meios e materiais expressivos das dinâmicas características de qualquer elemento do mundo perceptivo.

Por meio desta pesquisa, procurei mostrar que não se trata apenas de uma proximidade teórica entre Lecoq e Jousse, mas que houve movimentos intensionais da parte de Lecoq como forma de aprimorar sua pesquisa e seu ensino. E, é preciso sublinhar que, embora o valor da palavra escrita como veículo de ensino e aprendizagem fosse desacreditado por ambos, entendo que a publicação de L'Anthropologia du geste serviu como elemento de acesso de Lecoq ao pensamento joussiano.

Se há nobreza e determinada qualidade no ensino direto pela vivência para esses pesquisadores (Jousse e Lecoq) e seus alunos, há que se reconhecer que há também contribuições na propagação impressa de suas descobertas. Em medidas distintas, mas reais.

Acredito que uma teorização de elementos da pedagogia do teatro lecoquiano possa ser um complemento de seu ensino na medida em que se ocupa com processos e registros que Lecoq não se empenhou em fazer. E, assim, suprir uma lacuna.

Este trabalho visa, pois, contribuir no esclarecimento das propostas de mimo, segundo Lecoq. A bibliografia disponível em língua portuguesa sobre o teatro do gesto (teatro físico) ainda é escassa. Os elementos que foram apontados amparam as vivências dos ex-alunos dessa linhagem e oferece, portanto, subsídios para fundamentar práticas pedagógicas. Também penso ter trazido às pessoas interessadas nos "ecos" de Jousse, um melhor entendimento da vinculação de Lecoq. Nesse sentido, a documentação, depoimentos e teorias aqui apresentadas pretendem suprir lacunas teóricas e históricas, no Brasil e no exterior.

SCHEFFLER, Ismael. Jacques Lecoq e a antropologia do gesto de Marcel Jousse. PóS:Revista do Programa de Pós-graduação em Artes da EBA/UFMG. v.9, n.17: mai. 2019. Disponível em <https://eba.ufmg.br/revistapos>

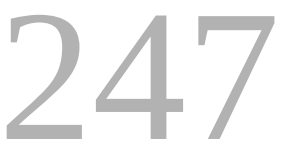


Saliento que o estudo sobre Jousse em conexões com Lecoq não se esgota neste artigo. Weiss (1972), De Marinis (1993), Freixe (2014) e Sachs (2013, 2016) oferecem também interessantes aspectos para reflexões. A pesquisa de Bya Braga (2013) sobre Decroux, considerando Jousse, pode oferecer interessantes subsídios sobre mimismo e rejogo. Muitas questões podem ser analisadas por meio dos escritos de Jousse, ainda mais acessíveis com a disponibilização pela internet de Les cours de Marcel Jousse.

Ressalto, por fim, a importância de se cultivar em língua portuguesa um vocabulário apropriado para abordar questões referentes ao mimo segundo Lecoq, elemento que foi importante para os estudos antropológicos de Jousse e que, como apontado, trouxe dificuldades para Lecoq.

\section{REFERÊNCIAS}

BARON, Gabrielle. Mémoire vivante: Vie et œuvre de Marcel Jousse. Paris: du Centurion, 1981.

BEAUCOUSIN, David. Du singulier à l'universel: emergence d'une pédagogie créatrice d'un langage poétique à l'école Lecoq. 2004. 79 f. Memoire DEA. Université de la Sorbonne Nouvelle - Paris 3, Paris, 2004.

BELEKHIAN, Krikor. Spetacle d'architectures portables. 1972. 16 f. Trabalho de diplomação (Graduação em Arquitetura) - École d'Architecture de Paris La Vilette. Paris, 1972.

BELLUGue, Paul. À propos de l'art de forme et de mouvement. Paris: Maloine, 1967.

BRAGA, Bya. Étienne Decroux e a artesania de ator - caminhadas para a soberania. Belo Horizonte: Ed. UFMG, 2013.

COUSIN, Gabriel. Mime et mouvement avec La Compagnie Jacques Lecoq. O texto foi publicado, mas na cópia existente no Fundo Cousin, na Biblioteca Nacional da França, não aparece a referência. Existe no arquivo também uma cópia datilografada datada de 1960. BnF, Fundo Gabriel Cousin : 4COL 81/362 (2).

DE MARINIS, Marco. Mimo e teatro nel Novecento. Firenze: La Casa Usher, 1993.

DULLIN, Charles. Souvenirs et notes de travail d'un acteur. Paris: Odette Lieutier, 1946.

SCHEFFLER, Ismael. Jacques Lecoq e a antropologia do gesto de Marcel Jousse.

PóS:Revista do Programa de Pós-graduação em Artes da EBA/UFMG. v.9, n.17: mai. 2019.

Disponível em <https://eba.ufmg.br/revistapos>

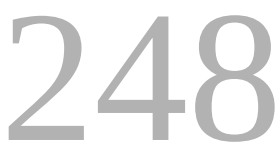


FELNER, Mira. Apostles of silence: the modern french mimes. London, Toronto: Assocoated University Presses, 1985.

FREIXE, Guy. La filiation Copeau-Lecoq-Mnouchkine : une ligée théâtrale du jeu de l'acteur. Lavérune: L'Entretemps, 2014.

FROST, Anthony; YARROW, Ralph. Jacques Lecoq and the semiotics of clowning. In: 73. . Improvisation in Drama. Nova Iorque: St. Martin's Press, 1990. p. 61-

FROMONT, M. F. L'enfant mimeur : l'anthropologie de Marcel Jousse et la pédagogie. Paris: Epi, 1978.

JOUIN, Nathalie. Le mouvement chez Etienne Decroux et Jacques Lecoq. 2007. 59 p. Dissertação (Master 1) - Institut de Recherches en Etudes Théâtrales, Université de la Sorbonne Nouvelle - Paris 3, Paris. 2007.

JOUSSE, Marcel. Mimétisme et mimisme. 4ème conférence. École d'Anthropologie. 28 nov. 1932. Le cours de Marcel Jousse. CD-room 1/2. Association Marcel Jousse, 2003.

L’anthropologie du geste. Paris: Gallimard, 2008.

LEABHART, Thomas. Modern and post-modern mime. Nova lorque: St. Martin's Press, 1989.

LECOQ, Jacques. Le mouvement et le théâter. Atac Information, n. 13, p. 07, 1967.

Du mime au théâtre - L'école Jacques Lecoq s'ouvre au public. T.E.P. (Théâtre de I'Est Parisien), Maison de la Culture, n.49, p. 5, oct. 1968.

Le corps et son image. Architecture d'Aujourd'hui, n. 152, p. CXXXVI e CXXXVII, oct./ nov. 1970.

L'école Jacques Lecoq (mime-mouvement-théâtre) au Théâtre de la Ville. Le Journal du Théâtre de la Ville, n. 15, [Paris], p. 41-42, 11 jan. 1972.

L'espressione física dell'attore. In: MARINIS, Marco de (Org.). Mimo e mimi: parole e immagini per um genere teatrale des Novecento. Firenze: La casa Usher, 1980. p. 201-205.

(Org.). Le Théâtre du Geste: mimes et acteurs. Paris: Bordas, 1987a.

Le geste sous le geste. Présentation par Jean Perret. In: Marcel Jousse, Du geste à la parole. Colloque public pour le Centenaire organisé par le Cente Sèvres et la Fondation Marcel Jousse avec la patronage de la Fondation de Montcheuil. 20-21 novembre 1986. Travaux et conférences du Centre Sèvres, n. 12. Paris: Centre Sèvres, 1987b. p. 5558.

SCHEFFLER, Ismael. Jacques Lecoq e a antropologia do gesto de Marcel Jousse.

PÓS:Revista do Programa de Pós-graduação em Artes da EBA/UFMG. v.9, n.17: mai. 2019.

Disponível em <https://eba.ufmg.br/revistapos>

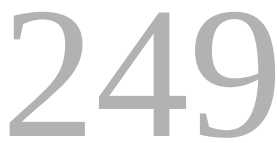


Le Corps Poétique : Un enseignement de la création théâtrale. Arles: Actes Sud - Papiers. Collection Cahiers Théâtre/Education (collection publiée par I'ANRAT - Association Nationale de Recherche et d'Action Théâtrale), 1997.

Theatre of Movement and Gesture. Londres: Routledge, 2006.

0 corpo poético: uma pedagogia da criação teatral. Trad.: Marcelo Gomes. São Paulo: SENAC São Paulo; SESC SP, 2010a.

LECOQ, Pascale. Entrevista a Ismael Scheffler com a participação de Antoine Blanchet na École International de Théâtre Jacques Lecoq. Paris, 12 de abr., 16 de maio de 2011. 3 arquivos de Áudio do Windows Media (.WMA) (85 min.) Francês. Entrevista.

LECOQ, Patrick. Jacques Lecoq, un point fixe en mouvement. Paris: Actes Sud-Papiers, 2016.

LES DEUX Voyages de Jacques Lecoq. Documentário realizado por: Jean-Noël Roy e Jean-Gabriel Carasso; co-produção: La Sept ARTE, On Line Productions, ANRAT. 1999. 1 DVD (175 min).

MAZAS, Alain. Entrevista concedida a Ismael Scheffler. 14 de agosto de 2012. 1 arquivo de Áudio do Windows Media (.WMA) (110 min.) Francês. Entrevista.

MERLANT, Christophe. L'Ecole Lecoq: des mouvements de la vie à la création vivante. In: GOURDON, Anne-Marie. Les nouvelles formations de l'interprète : Théâtre, danse, cirque, marionettes. Paris: CNRS, 2004. p. 59-71.

MOUNIN, Georges. Le mime contemporain. In: Introduction à la sémiologie. Paris: Minuit, 1970. p. 169-181.

MURRAY, Simon. Jacques Lecoq. Londres: Routledge, 2003.

PERRET, Jean. Jacques Lecoq: d'abord le movement. Treteaux, n. 6, p. 54-58, nov. 1967.

RITORNO all'espressione fisica dell'attore. Atti della tavola rotonda Internazionale del 19 settembre 1969. La Biennale di Venezia, XXVIII Festival Internazional des Teatro di Prosa, 1969. Venezia: Nouva Editoriale, 11 set. 1970.

ROLFE, Bari. The Mime of Jacques Lecoq. The Drama Review: TDR. v. 16, n. 1, p. 3438, mar. 1972.

SACHS, Cláudia M. A imaginação é um músculo : a contribuição de Lecoq para o trabalho do ator. 2013. 224 f. Tese (Doutorado em Teatro) - Universidade do Estado de Santa Catarina, Programa de Pós-Graduação em Teatro, 2013.

Bachelard, Jousse and Lecoq. In. EVANS, Mark Evans ; KEMP, Rick. The Routledge Companion to Jacques Lecoq. Londres: Routledge, 2016. p.51-58.

SCHEFFLER, Ismael. Jacques Lecoq e a antropologia do gesto de Marcel Jousse.

PÓS:Revista do Programa de Pós-graduação em Artes da EBA/UFMG. v.9, n.17: mai. 2019.

Disponível em <https://eba.ufmg.br/revistapos>

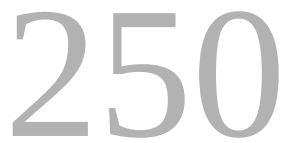


SCHEFFLER, Ismael. O Laboratório de Estudo do Movimento e o percurso de formação de Jacques Lecoq. 2013. 591 f. Tese (Doutorado em Teatro) - Universidade do Estado de Santa Catarina, Programa de Pós-Graduação em Teatro, 2013.

. Laboratory of Movement Study. In. EVANS, Mark Evans ; KEMP, Rick. The Routledge Companion to Jacques Lecoq. Londres: Routledge, 2016. p. 179-186.

Atuação docente de Jacques Lecoq na formação de arquitetos: laboratórios de cenografia experimental. Revista Arte da Cena (Art on Stage), v. 4, n. 2, jul.-dez. 2018. p. 34-64. Disponível em: https://www.revistas.ufg.br/artce/article/view/54973 Acesso em : 23 fev. 2019.

. Arquiteturas portáteis: a pesquisa de diplomação em Arquitetura de Krikor Belekian sob a orientação de Jacques Lecoq. Anais do X Congresso da ABRACE - Associação Brasileira de Pesquisas e Pós-graduação em Artes Cênicas, 15 a 20 de outubro de 2018. Natal, RN. v. 19, n. 1, 2018. Disponível em: https://www.publionline.iar.unicamp.br/index.php/abrace/article/view/4054/4169 Acesso em: 02 jun. 2019.

. Jacques Lecoq e o Laboratório de Estudos do Movimento (LEM): da escola de arquitetura a um espaço autônomo de cenografia experimental. Revista Cena, n. 27, jan./ abr. 2019. p. 47-59. Disponível em: https://seer.ufrgs.br/cena/article/view/87785 Acesso em 23 fev. 2019.

STEFANESCO, Lucien. La formation corporelle de l'acteur au XXe siècle : l'école Jacques Lecoq. 1972. 268 p. Tese (Doutorado) - Institut d'Etudes Théâtrales, Université de la Sorbonne Nouvelle - Paris 3, Paris, 1972.

SUR LES PAS de Marcel Jousse. Documentário realizado por Jean-Claude Cheyssial e produzido cientificamente por Jean-Rémi Lapaire; coproduzido pela Université Bordeaux Montaigne e Association Marcel Jousse. 2014. (52 min). Disponível em: http://www.marceljousse.com/sur-les-pas-de-marcel-jousse-2014/ Acesso em: 08 jan. 2019.

UN ORIGINAL. John Harvrd's Journal. Harvard Magazine. Harvard University. 01 mar. 2000. Disponível em: https://harvardmagazine.com/2000/03/un-original-html Acesso em: 15 jan. 2019.

WEISS, Willian. Du mime a l'art mimique. Memoire de Maîtrise. 1972. 204 f. Institut d'Études Théâtrales. Université de la Sorbonne Nouvelle Paris III, Paris, 1972.

WYLIE, Laurence. A l'école Lecoq j'ai découvert mon propre clown. Revue Psychologie, Paris, n. 43, p. 17-27, ago. 1973.

SCHEFFLER, Ismael. Jacques Lecoq e a antropologia do gesto de Marcel Jousse.

PÓS:Revista do Programa de Pós-graduação em Artes da EBA/UFMG. v.9, n.17: mai. 2019.

Disponível em <https://eba.ufmg.br/revistapos>

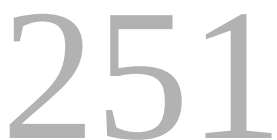




\section{NOTAS}

1 No âmbito teatral brasileiro, no que pude apurar até o momento, Jousse é estudado por Braga (2013), em sua pesquisa sobre Étienne Decroux (páginas 172, 173 e 451); também por Sachs (2013, 2016) e Scheffler $(2013,2016)$ relacionando a Lecoq.

2 SCHEFFLER, Ismael. O Laboratório de Estudo do Movimento e o percurso de formação de Jacques Lecoq. 2013. 591 f. Tese (Doutorado em Teatro) - Universidade do Estado de Santa Catarina, Programa de Pós-Graduação em Teatro, 2013. Orientação: Prof. Dr. José Ronaldo Faleiro. Apoio: bolsa sanduíche PSDE/ CAPES.

3 Todas as traduções de fontes em línguas estrangeiras foram feitas pelo autor do presente artigo.

4 Marco de Marinis (1993) relacionou os nomes: École de Mime: Formation du Comédien; École de Mime et de Théâtre; École Lecoq: Mime, Mouvement, Théâtre; École Internationale de Théâtre Jacques Lecoq.

5 As questões comparativas entre Lecoq e Decroux suplantam discussões estéticas, conceituais e pedagógicas. Parece existir uma disputa ou rivalidade (LEABHART, 1989; DE MARINIS, 1993; MURRAY, 2003), ou certo mal-estar que transcende a relação entre ambos falecidos, tomando seus ex-alunos (por vezes, mesmo que de linhagem indireta). Não cabe a presente pesquisa aprofundar o tema neste sentido pois foge do objetivo e requer atenta metodologia, fontes e parcimônia no trato.

$6 \quad \mathrm{Na}$ Biblioteca Nacional da França, encontra-se uma compilação de críticas jornalísticas publicadas sobre este espetáculo: BnF: 8-SW-1237.

7 GAUTIER, Jean-Jacques. À l'Alliance Française «Carnet de Voyage». Le Figaro, 16 octobre 1959. BnF: 8-SW-1237.

8 MARCALERIE, P. Carnet de Voyage indéchiffrable. Arts. 21/10/1959. BnF: 8-SW-1237.

9 JAUBERT, J.C. Au théâtre de l'Aliance Française «Carnet de voyage» autour du mime. Parisien Libéré. 19/10/59. BnF: 8-SW-1237.

10 COUSIN, Gabriel. Mime et mouvement avec La Compagnie Jacques Lecoq. O texto foi publicado mas na cópia existente no Fundo Cousin da Biblioteca Nacional da França não aparece a referência, somente as páginas 39-40. Existe também uma cópia datilografada datada de 1960. BnF, Fundo Gabriel Cousin: 4COL 81/362 (2).

11 Publicado em 1987, tem organização de Jacques Lecoq e contribuições de diversas pessoas. Lecoq assinou quatro artigos principais: L'imitation: du mimétisme au mimisme [A imitação: do mimetismo ao mimismo] ; Les gestes de la vie [Os gestos da vida] ; De la pantomime au mime moderne [Da pantomima ao mimo moderno] ; Le mime, art du mouvement [O mimo, arte do movimento]. Além dos quatro artigos, Lecoq inseriu ao longo da entrevista La pédagogie $d u$ Mouvement [A pedagogia do movimento], concedida a Jean Perret, caixas de texto destinadas a cada um dos seguintes temas: Como se move um coro?; Sobre a commedia dell'arte; O jogo da máscara; A procura de seu próprio palhaço; O tempo dos bufões; Os quadros mimados; O jogo das estruturas portáteis [Comment bouge un choeur; À propos de la commedia dell'arte; Le jeu du masque; À la recherche de son propre clown; Le temps des bouffons; Les bandes mimées; Le jeu des structures portables.]

12 Acredito tratar-se de um curso específico, e não uma transferência da escola, pois em nenhuma outra fonte há indicação que a escola como um todo tenha se transferido para Amiens. 


\section{NOTAS}

13 A publicação é de outubro, embora o texto esteja assinado como maio.

14 François Delsarte (1811-1871).

15 Freixe (2014) refere que Gordon Craig, em sua Escola da Arena Goldoni, sob influência de Isadora Duncan, propunha exercícios neste sentido. Copeau visitou Craig, em 1915, e acompanhou algumas aulas em sua escola, o que poderia ser um caminho de influência. Duncan, por sua vez, teve influências de Delsarte em sua formação, o que leva a mesma fonte apontada por Stefanesco (1972).

16 As discussões foram desenvolvidas na manhã e tarde deste dia e posteriormente publicadas em italiano em um volume de 57 páginas. A mesa foi presidida por Jacques Lecoq e composta pelas seguintes pessoas: Jacques Bosson, Georges Moulin, Andre Veinstein, Martin Esslin, Nicola Chiaromonte, Giuseppe Di Martino, Giovanni Poli. Entre outros temas, também foi tratado sobre o início da proposta com alunos de arquitetura. Documento disponível na Biblioteca Nacional da França, código 8-W-18676. - Marco De Marinis apresentou algumas falas de Lecoq, em forma textual, sem incluir os demais membros da mesa ou as perguntas feitas a Lecoq (por isso o texto se apresenta de forma fragmentada), sob o título L'espressione fisica dell'attore [A expressão física do ator] (LECOQ, 1980), no livro Mimo e mimi: parole e immagini per um genere teatrale del Novecento [Mimo e mimos: palavras e imagens para um gênero teatral do século XX], um livro no qual há uma compilação de textos de autores diferentes.

17 Para saber mais a esse respeito, ver os artigos complementares: Atuação docente de Jacques Lecoq na formação de arquitetos: laboratórios de cenografia experimental (SCHEFFLER, 2018); Jacques Lecoq e o Laboratório de Estudos do Movimento (LEM): da escola de arquitetura a um espaço autônomo de cenografia experimental (SCHEFFLER, 2019).

18 Há uma reprodução do artigo em Jacques Lecoq, um point fixe em mouvement (LECOQ, P., 2016).

19 Sua tese utiliza a pouca bibliografia publicada até então, as entrevitas com Lecoq e, significativamente, sua experiência como aluno, sendo, provavelmente, o primeiro estudo mais amplo sobre a pedagogia de Lecoq.

20 Ver o artigo: Arquiteturas portáteis: a pesquisa de diplomação em Arquitetura de Krikor Belekian sob a orientação de Jacques Lecoq (SCHEFFLER, 2018).

21 Wylie também mencionou e incluiu duas citações de Paul Bellugue, de À propos de l'art de forme et de mouvement [Sobre a arte de forma e movimento] (1967). Neste livro, no capítulo Morphologie, esthétique gestuelle et art de vivre [Morfologia, estética gestual e arte de viver], Bellugue declara que sua compreensão de gesto estava relacionada à forma ampla como o antropólogo Marcel Jousse trabalhava com o termo. - Paul Bellugue (1892-1955) foi professor titular da cadeira de anatomia artística junto a Escola Nacional Superior de Belas Artes (de 1936 a 1955) e professor de anatomia, morfologia e estética na Escola Normal de Educação Física (de 1943 a 1955). Desenvolveu uma interessante carreira articulando estudos científicos e artísticos sobre o movimento, estabelecendo diálogo entre as artes visuais, as artes cênicas, o esporte e a ciência. Bellugue também é referido na bibliografia de Belekian (1972) e em Le thêátre du geste (LECOQ, 1987a). Para mais aprofundamento ver: SCHEFFLER, 2013.

22 De Marinis (1993) distinguiu o mimo como um gênero autônomo e específico (estrito), de um mimo voltado a educação (mais amplo), sendo este o de interesse de Lecoq.

23 No ano letivo de 2010-2011, fui aluno no LEM, tendo acompanhando as aulas de Krikor Belekian e Pascale Lecoq. 


\section{NOTAS}

24 Archives de philosophie, vol. II, cahier 4, Beauchesne, Paris, 1924.

25 Disponível em: < http://www.marceljousse.com/les-cours-de-marcel-joussedisponibles-en-telechargement/>, desde abril de 2018.

26 Em 1968, era Fundation Marcel Jousse, passando, em 1986, a Association Marcel Jousse.

27 Alain Mazas nasceu no Marrocos e teve formação em escola jesuíta, onde também trabalhou como professor. Em 1974, mudou para Paris buscando uma reorientação profissional, dirigindo-se à formação em paisagismo, atividade que exerce desde então. Trabalhou como paisagista rodoviário e na elaboração do primeiro atlas de paisagens da França.

28 A brochura conta com 5 artigos e a transcrição de uma mesa-redonda. Agradeço a Jean Ghislain d'Eudeville, presidente da Association Marcel Jousse, pelo envio da publicação.

29 O site não informa a qual evento se refere. Disponível em:

$<$ http://www.marceljousse.com/echos-et-prolongements/jousse-vu-entendu-lu-par-des-personnalites/ >. Acesso em: 7 jan. 2019. 